\title{
EL PAPEL DEL UTILITARISMO \\ EN EL DESARROLLO \\ DE LA CIENCIA ECONOMICA \\ Y LA CIENCIA POLITICA
}

JOSEP M. COLOMER

Universidad Autónoma de Barcelona

\section{Presentación *}

Este papel puede mostrar una cierta añoranza de la economía política y pretende ser una modesta invitación al diálogo y la comunicación entre la ciencia económica y la ciencia política. Muestra también una cierta afición del autor a descubrir en las teorías actuales conceptos y relaciones establecidas o apuntados por los autores clásicos.

Ambos gustos encuentran un campo especialmente atractivo en el estudio del utilitarismo, hasta el punto de que lo que aquí se viene a argumentar es que la dilatada obra de Jeremy Bentham contenía ya, en esbozos desigualmente desarrollados, casi todo el ciclo de razonamiento de más de un siglo de discursiones de la ciencia económica y la ciencia política posteriores a él: primero, la confianza en el diseño de una función de bienestar general para la sociedad; después, la sospecha acerca de los medios políticos de agregación de las preferencias individuales en esa función de bienestar social; finalmente, la dificultad de conciliar la prioridad a los medios políticos democráticos con los incentivos para que los individuos adopten comportamientos morales.

\section{Algunas aportaciones de los clásicos ingleses}

Si nos remontamos a la economía política clásica y, en particular, a las tendencias menos dogmáticas e idealistas de la Ilustración del siglo xvin, podemos encontrar ya algunas aportaciones a la formación del pensamiento utilitarista que han fundamentado el desarrollo de una buena parte de la ciencia económica y la ciencia política.

* El esquema aquí presentado está más desarrollado y documentado en mi libro El uti. litarismo. Una leoria de la elección racional (Editorial Montesinos, 1987). Se ha prescindido aquí de todo aparato bibliográfico. 
Estos elementos primigenios pueden ser recapitulados como sigue:

- supuesto de que los intereses, las pasiones y la búsqueda del placer son las motivaciones básicas de las conductas humanas;

- observación de que de tales comportamientos egoístas se derivan efectos no queridos, tanto de utilidad recíproca como de conflicto;

- necesidad consiguiente de incentivos para la armonización artificial de intereses, bien sea mediante la estimulación de sentimientos morales de tipo simpatético o benévolo, la educación o la acción política y legislativa.

Basándose en tales supuestos y valores, la formalización del utilitarismo por Jeremy Bentham (1748-1832) implicó inicialmente la ambición de conseguir una teoría explicativa y normativa al mismo tiempo.

El individualismo metodológico, anejo a la opción ética por la igual dignidad de todos los individuos, supone que la definición de un interés colectivo no puede realizarse al margen de los deseos manifestados por los individuos ni cabe atribuir a éstos intereses que no sean identificados por ellos como tales.

El primer Bentham (Introduction to the principles of morals and legislation, 1789) derivaba de ello que el interés de la comunidad es la suma de los intereses de sus distintos miembros, por lo que debía suponer que la utilidad es mensurable, según unas dimensiones de la misma (intensidad, duración, certeza, proximidad) que permiten una aritmética moral.

Sin embargo, este enfoque no implica que la agregación de los intereses individuales se vaya a realizar mediante una armonización natural, al estilo de la mano invisible de Adam Smith, ni tampoco la aceptación resignada de los efectos sociales irracionales de los comportamientos individuales egoístas. Por el contrario, como ha subrayado W. Stark, Bentham, basándose en el concepto de utilidad marginal decreciente, según el cual el placer obtenido con una porción de dinero es menor cuanta mayor sea la riqueza del individuo, establece la conveniencia de una intervención redistributiva de los poderes públicos para maximizar la felicidad general.

El segundo Bentham o Bentham maduro introdujo importantes cambios a este planteamiento inicial. En Constitutional Code (1832) Bentham argumenta a favor de la democracia basándose en una extensión del supuesto analítico de la autopreferencia a la conducta de los gobernantes. Abandonando la confianza ilustrada en algún déspota benevolente, Bentham advierte el conflicto entre los intereses de la minoría gobernante y los intereses de la mayoría gobernada y sostiene, consiguientemente, que el poder soberano debe estar en manos de aquellos cuyo interés sea la máxima felicidad, es decir, todos los ciudadanos. Como ha señalado H. L. Hart, en esta obra de Bentham los 
gobernantes son contemplados como un grupo de criminales en potencia, sospechosos por el hecho de serlo, que deben ser objeto de incentivos externos para conseguir que actúen de acuerdo con su utilidad general. El suyo debe ser, por tanto, un poder subordinado al control del público según los principios de mínima confianza y máxima responsabilidad. La democracia aparece así como una condición para la armonización artificial de intereses entre gobernantes y gobernados. Si cada individuo es el mejor juez de sus intereses, todos los individuos serán los mejores jueces y los más seguros protectores del interés general.

Esta evolución en el pensamiento de Bentham -a menudo ignorada en algunos manuales - comporta una revisión del concepto de utilidad y de la dimensión normativa de la teoría utilitarista.

La acentuada importancia del supuesto de la autopreferencia conlleva que se tienda a identificar la felicidad con aquello que los individuos entienden por felicidad y, en última instancia, dada la diversidad de sentimientos y concepciones en la materia, con los deseos humanos. Se distingue así, por un lado, la felicidad individual, buscada privadamente por cada individuo mediante la defensa de sus propios intereses según la prudencia o cálculo, y, por otro lado, el principio de la utilidad, como guía de la legislación y el gobierno con el fin de orientar y limitar las acciones humanas. Este cambio de énfasis en la concepción de la felicidad condujo a Bentham a olvidar la idea de una aritmética moral, que suponía la posibilidad de medición y comparación de los placeres y dolores de las distintas personas.

De este modo, el utilitarismo del Bentham maduro ya no aspira a ser una teoría moral sustantiva sobre el bien y el mal (que pudieran administrar los gobernantes), sino que se limita a ser una teoría axiológica que afirma la bondad de la búsqueda de la felicidad y de la máxima realización de los deseos y preferencias de los individuos (por los que sólo puede aplicarse en un régimen democrático). Así como la ilustración dieciochesca y el primer Bentham podían confiar en los gobernantes ilustrados para la realización de la utilidad pública concebida como la suma de las utilidades individuales, en democracia hay que replantear los modos de agregación de las preferencias individuales para que repercutan en beneficio de un interés común.

Pero, según la visión de Bentham, también en democracia caben coaliciones mayoristas de intereses perversos, es decir, de intereses particulares que menoscaban el interés público y que pueden alcanzar su predominio a través de las mayorías parlamentarias. Como ha señalado J. Streintrager, se da la paradoja de que el propio énfasis de la teoría democrática benthamiana en la desconfianza con respecto al gobierno puede contribuir a erosionar toda la tensión ética orientada a fines de utilidad colectiva y predisponer incluso a los individuos a una actitud desconfiada y de sospecha con respecto a los ciudadanos. 
Así pues, la democracia puede estimular conductas egoístas de individuos y grupos en las que la racional persecución de sus propios intereses particulares genere nuevos medios de perjuicio a los demás.

En su obra póstuma Deontology (1834), Bentham parece apuntar una solución en la rehabilitación del sentimiento de benevolencia (también llamado a veces probidad, obsequiosidad o deferencia). Se trata de un sentimiento emparentado con la virtud a la que David Hume llamaba simpatía (o instinto basado en el sentimiento de compartir como los demás hombres una misma naturaleza básica), aunque el subjetivismo de la teoría moral humana es considerada por Bentham como una peligrosa fuente de intolerancia y desprecio hacia los indiferentes y los débiles. Se trataría para Bentham de promover un sentimiento de bienquerencia hacia todos los sufrimientos, un esfuerzo por aliviarlos y una voluntad de bien que haga de la felicidad humana su objeto de atención y su meta. Se subraya así la necesidad de introducir motivos para que los individuos actúen de un modo distinto a como lo hacen si siguen únicamente su propio interés.

La obra de John Stuart Mill (1806-1873) fue, en cierto modo, una crítica y revisión del primer sistema de pensamiento benthamiano.

Cabe señalar ahora sólo algunas de sus aportaciones en Principles of Political Economy (1848).

En primer lugar, la teoría analítica de la utilidad recíproca del intercambio, expuesta por Adam Smith, es refinada por Mill con su teoría de las ventajas comparativas y la distribución de las ganancias del comercio, de modo que se convierte en la base de un programa de progreso moral para el futuro de la humanidad.

En segundo lugar, sus vacilaciones en torno a la conveniencia o perjuicio del intervencionismo de los poderes públicos desembocan en la defensa del laisser-faire como uno de los principios secundarios derivados del principio de la utilidad, pero con excepciones suficientemente numerosas como para que en él se pueda percibir un precedente de la teoría de los fallos del mercado.

Finalmente, la idea de la cooperación entre los hombres completa también su diseño, al modo de la simpatía de Hume o la benevolencia de Bentham, como un resorte moral para evitar las consecuencias socialmente perniciosas de la persecución individual del propio interés a corto plazo.

\section{El utilitarismo en la teoría económica del bienestar}

Estas y otras aportaciones de los fundadores del utilitarismo han desempenado papel en cierto modo fundacional en el desarrollo de la ciencia económica y la ciencia política de nuestro siglo. 
La formalización de estas disciplinas requirió, en primer lugar, una más clara delimitación entre teoría normativa y teoría explicativa con respecto a la tradición ilustrada.

Ya Henri Sidgwick distinguió los dos aspectos. Por un lado, Sidgwick contempló el primer principio ético del utilitarismo - la maximización de la felicidad- como una opción no demostrable racionalmente (aunque su tentativa de fundamentación por la intuición mereció también la crítica axiológica de G. E. Moore en su análisis de los principios y de los juicios morales). Por otro lado, reafirmo el supuesto de que los individuos normalmente persiguen en las acciones voluntarias su propia felicidad o placer como apoyo de una teoría analítica de las conductas humanas. En este aspecto, Sidgwick aceptó como legítimas algunas críticas al utilitarismo realizadas en nombre de la diversidad histórica y cultural de la experiencia de la humanidad y delimitó la validez explicativa de tales motivaciones en «la historia reciente del nuestro y otros países civilizados" (The Method of Ethics, 1874).

La teoría económica alcanzó desde entonces un notable desarrollo, a partir del supuesto simplificador de origen utilitarista de que el bienestar material es uno de los factores de la felicidad.

Así, se advierte claramente la inspiración utilitarista en los principales elementos utilizados en un principio en la elaboración de la teoría económica del bienestar:

- La teoría del valor subjetivo, ya elaborada por Bentham y retomada por los economistas marginalistas para definir las condiciones formales de una óptima asignación de recursos;

- La teoría de los fallos o fracasos del mercado, ya apuntada por Bentham, Mill y Sidgwick como divergencia entre la utilidad privada obtenida por un empresario o consumidor en una determinada actividad y la utilidad social provocada por ésta, y sistematizada posteriormente como divergencias entre el producto privado y el producto social y como economías y deseconomías externas o externalidades, válidas para determinar las medidas más convenientes de la intervención estatal;

- Un criterio ético igualitario de distribución de la felicidad entre los miembros de la sociedad, igualmente avanzado por los utilitaristas clásicos a partir de la idea de la utilidad marginal decreciente, para aproximarse a las condiciones de maximización del bienestar.

Como es sabido, uno de los grandes debates sobre la teoría económica del bienestar alcanzó de lleno al tema clásico de la comparabilidad y mensurabilidad de la utilidad experimentada por las distintas personas. Tanto en el utilitarismo del primer Bentham como en la vieja teoría económica del bienestar 
de Pigou se usa una idea de la utilidad individual como algo medible cuantitativamente y de la utilidad social como suma de las utilidades individuales, en el segundo caso homogeneizando las satisfacciones proporcionadas por los bienes por el común valor monetario de éstos y midiéndolas a través de las cantidades de dinero que un individuo está dispuesto a pagar por ellos. Entre los marginalistas coexistió ya la mensurabilidad cuantitativa o cardinal con una comparabilidad solamente ordinal. Pero en la nueva teoría económica del bienestar, que se basa en planteamientos paretianos, se usan sólo indiferencias y ordenaciones de preferencias por parte de los individuos y relaciones de sustitución. Por todo ello, la formulación neoutilitarista de Abraham Bergson (1938) redefinió el bienestar global de la sociedad como una función creciente de las funciones de utilidad individuales, concibiendo una función de utilidad para cada individuo sin necesidad de atribuir a esta utilidad una dimensión cuantitativa ni de suponer que los individuos tengan los mismos gustos y temperamentos y sus utilidades marginales vayan a ser iguales en una situación igualitaria.

Se produjo así un visible cambio de énfasis en el concepto de utilidad. Mientras el primer Bentham creía poder medir la felicidad y la vieja teoría económica del bienestar concebía la utilidad como la satisfacción mensurable de los individuos, la evolución tardía de Bentham y el neoutilitarismo sólo se permiten definir la utilidad de los individuos a partir de sus deseos manifestados o «preferencias reveladas». También en el proceso reciente se ha acentuado la importancia del supuesto de la autopreferencia, hasta el punto de definir la utilidad y lo útil como lo que corresponde a sus deseos y preferencias. La pérdida de un determinado contenido sustantivo de la utilidad o bienestar económico conlleva el peligro de un cierto planteamiento tautológico: el comportamiento del individuo se explica en función de sus preferencias, pero éstas sólo se conocen cuando se manifiestan o revelan a través del comportamiento.

Esta condición algo evanescente del nuevo concepto de utilidad reduce la dimensión normativa de la teoría, de modo que la función de bienestar social puede aparecer como un criterio meramente axiológico favorable a la realización de las preferencias y deseos humanos, pero sin mayor operatividad en cuanto a decisiones sustantivas concretas.

Así, pues, la evolución teórica de la economía del bienestar sugiere un llamativo paralelismo con una cierta evolución del utilitarismo clásico. Así como para Bentham el cálculo felicífico o aritmética moral no resultaba viable sin la medición y comparabilidad de placeres y dolores —reducidos a los perceptibles por los sentidos-, también la teoría económica del bienestar tropieza con análogas dificultades en su cálculo maximizador — basado en una nueva 
reducción de su objeto, esta vez a los factores económicos de la felicidad humana.

Asimismo, la redefinición del fin ético como la máxima realización de las preferencias y deseos de los individuos vuelve a situar en primer plano - como en la evolución del utilitarismo clásico- la cuestión de la intermediación política; en este caso, la problemática cuestión de los mecanismos procedimentales e institucionales de elección individual y de agregación de las preferencias individuales en una función de bienestar social.

\section{El análisis «económico» de la politica}

Pero el teorema de la imposibilidad de Kenneth Arrow llamó la atención sobre las irracionalidades en la elección colectiva, manifestadas en resultados alternativos y cambios cíclicos. Si una ordenación social de preferencias resulta globalmente inconsistente con las ordenaciones individuales de preferencias en las que pretende basarse, hay que suponer que en el proceso mismo de agregación se introducen criterios de elección que introducen determinadas preferencias sin respetar las condiciones de racionalidad formal.

Ello plantea inquietantes interrogantes sobre el proceso de agregación, que es un proceso fundamentalmente político. Hasta los años cincuenta, la teoría económica del bienestar había supuesto implícitamente que la definición de los criterios de un óptimo sería suficiente para que la intermediación política pudiera ajustarse a ellos, de un modo en cierta forma análogo a como el primer Bentham confiaba en un déspota benévolo que pudiera gobernar según el principio de la utilidad. En el enfoque economicista del bienestar, las instituciones y los poderes estatales venían a ser considerados como una variable exógena que no influía en la determinación de las preferencias y la expresión de los deseos de consumidores, trabajadores y empresarios en los que supuestamente se basaba la función de bienestar social. Con el interrogante abierto por Arrow se planteó, en cambio, la necesidad de investigar acerca de cuáles pueden ser los criterios de elección no derivados de esas preferencias individuales que son introducidos por los agentes del proceso de agregación; es decir, la investigación sobre las que podrían llamarse funciones de utilidad de los agentes de las instituciones y poderes que intervienen en el proceso político: electorado, partidos, gobierno, parlamento, burocracia, grupos de presión, etc. Se supone que esas personas también intentan maximizar racionalmente su propia utilidad, es decir, que actúan de acuerdo con la persecución de sus propios intereses (dentro de los límites que las instituciones les permiten). 
Así, aplicando los mismos supuestos metodolóigos básicos del utilitarismo, se ha desarrollado desde entonces lo que algunos llaman «teoría económica de la política» (o teoría política de la elección racional, teoría de la elección pública), es decir, el análisis de las motivaciones específicas de los individuos que componen tales grupos y organizaciones y los efectos de su acción no previstos ni por la teoría económica ni por la teoría política tradicionales. Este enfoque viene a terminar con la ilusión de un Estado benefactor, heredera de la confianza en un déspota benevolente del primer Bentham y, en cierto modo, también del proyecto de John Stuart Mill de una aristocracia intelectual que gobernara en aras de la educación moral de los súbditos.

Así, los poderes públicos ya no son concebidos como agentes asépticos de una política óptima externamente definida, sino como campos en los que se desarrollan y entrecruzan las jerarquías de preferencias de los individuos que intervienen en el proceso político y en los que se alteran, por lo tanto, los equilibrios de eficiencia en la asignación de recursos y de distribución del bienestar que pudieran establecerse con criterios puramente económicos.

Se parte, pues, de la presunción de que todos los individuos tienen en todos los campos de actividad motivaciones sustancialmente iguales, «dada la inalterable constitución de la naturaleza humana», como decía Bentham al advertir el egoísmo de los gobernantes. En definitiva, un individuo es el mismo cuando actúa como consumidor que cuando lo hace como elector, cuando ejerce de empresario que cuando es contratado como burócrata en la administración pública. Desaparece así el supuesto implícito de esquizofrenia de la ciencia económica y la ciencia política convencionales, según el cual los consumidores buscan satisfacer sus propios intereses privados al comprar ropas o alimentos $\mathrm{y}$, en cambio, se mueven por una visión altruista del interés público al votar o participar en la acción colectiva, al modo, digamos, de Mr. Hyde y el Dr. Jekyll.

La motivación racionalmente egoísta se concreta en la persecución de unos fines específicos por parte de los distintos agentes; así, puede suponerse que los votantes y demandantes de bienes públicos intentan maximizar los beneficios obtenidos de las políticas estatales, cabe presumir que los candidatos y gobernantes aspiran a obtener y mantener los cargos públicos, se postula que los burócratas actúan con el afán de aumentar al máximo los recursos administrativos a su disposición.

Sin embargo, la hipótesis de búsqueda del propio interés no comporta conformidad con las consecuencias irracionales del comportamiento egoísta de los individuos en sociedad; por el contrario, constituye una hipótesis adecuada para establecer incentivos y restricciones a la conducta individual que permitan obtener resultados socialmente benéficos. 
En los análisis que han seguido a las obras pioneras de Downs sobre el mercado electoral de votantes y partidos, en los de Niskanen sobre la burocracia, en los de Olson sobre los grupos de presión, etc., se reproducen, depuran y formalizan algunas viejas ideas de los clásicos del utilitarismo: reaparecen las coaliciones mayoritarias de intereses perversos en las mayorías con programas formados por adición de políticas que favorecen las preferencias intensas de determinadas minorías organizadas y posponen otras, en la tendencia a una creciente actividad de los grupos de presión, en la capacidad de negociación de los burócratas, etc.

En conjunto, vuelve a mostrar su vitalidad la idea de que las decisiones individuales, independientemente de sus motivaciones e intenciones, tienen efectos externos no queridos que interfieren en la persecución de sus intereses por los individuos. Esta idea se convirtió en la teoría económica del bienestar en el concepto de externalidades que permitía poner de manifiesto los fallos o fracasos del mercado en la consecución de un óptimo y, aplicada a la medición política, permite comprender fallos o fracasos del Estado en la consecución de aquel mismo objetivo.

La ciencia política encuentra así una vía decisiva de renovación. Según W. H. Riker, el enfoque de la elección racional ha sido «the main line of its development during the last generation (...) Although there are good reason to believe that rational choice analysis is the traditional paradigm of politics, just as it has been for economics, political scientists have on the whole never quite adopted the rational model as a generally accepted paradigm. Now that our understanding of the paradigs has become conscious and explicit, we have begun to exploit the technique of rational choice analysis and it seems reasonable to expect that, as we learn how to use it better, we will be more successful perhaps even as successful as economists» [Political Theory and the Art of Herestbetics, en Ada Finifter (ed.): Political Science. The State of the Discipline, American Political Science Association, 1983].

\section{Reglas del juego y moral}

Por otro lado, una vez declarada imposible la óptima agregación de preferencias en una función de bienestar social y abandonado el sueño del déspota benevolente, la atención normativa se orienta hacia el acuerdo sobre las condiciones del proceso político más que sobre el contenido de las decisiones que de él se tomen, de modo que puede considerarse que el interés público se constituye sobre todo en torno a las reglas para decidir. Dadas las irracionalidades e inconsistencias que aparecen en la elección colectiva, el análisis se ha ido orientando hacia las reglas de decisión, que algunos autores han llamado 
funciones de decisión social, como alternativa a las funciones de bienestar social. Los economistas han vuelto a interesarse así por la regulación de procesos que desde finales del siglo xix habían quedado en manos de los politólogos: cómo se presentan las opciones a elegir, quién hace las preguntas, cómo se vota, es decir, las «reglas del juego» (los procedimientos e instituciones) del proceso político.

El cálculo de la felicidad de Bentham, que se había reducido ya a cálculo del bienestar económico en Pigou, se trastoca así en cálculo del consenso (según el significativo título del libro de Buchanan y Tullock). Dada la inviabilidad de alcanzar un óptimo al estilo de la función de bienestar social bergsoniana, las reglas de decisión que podrán considerarse mejores serán aquellas que estimulen la revelación de preferencias de los grupos no organizados, el intercambio y la negociación entre el mayor número de individuos $\mathrm{y}$, en general, impidan en lo posible la explotación del grande por el pequeño (es decir, de la mayoría por las minorías). De este enfoque se deriva una apreciación favorable del regateo, el intercambio de votos, las coaliciones y la concertación, como medios para evitar la paradoja de las mayorías cíclicas y la toma sucesiva de decisiones distintas sobre los mismos temas.

Lo significativo de todo ello es que se conciben las instituciones y procedimientos de decisión política, no ya como medios para obtener resultados óptimos, sino para conciliar intereses en conflicto, al margen de la beligerancia entre fines morales. El problema que hoy se analiza es la elección racional del individuo entre distintas reglas posibles de toma de decisiones, pero sin pretender ya que con ellas se vayan a obtener fines de máximo bienestar social u otros parecidos. En este sentido, el enfoque de la teoría de la elección social es en cierto modo posutilitarista. La moral no es ya un asunto de ideales que la política debería hacer realidad, sino una cuestión de límites convencionales impuestos a las conductas individuales que persiguen su propio interés, para evitar grandes perjuicios a los demás y ciertos efectos negativos más allá del corto plazo.

También ahora cabe inferir que una mayor conciencia de la falta de correspondencia entre la agregación colectiva de las decisiones y la racionalidad de las ordenaciones individuales puede inducir a los individuos a adoptar en mayor medida comportamientos estratégicos, es decir, a la revelación falseada de sus preferencias con el fin de obtener los resultados colectivos deseados a través del proceso deformante de agregación. De ahí, probablemente, que en la filosofía moral de los últimos tiempos haya habido nuevas rehabilitaciones de la benevolencia, la simpatía y la cooperación como criterios normativos de conducta social.

En resumen, el concepto de utilidad, al asociarse a la satisfacción de deseos y preferencias, ha llegado a identificarse con el mismo acto de elegir. La nueva 
teoría de la elección colectiva se orienta, más que a una racionalidad sustantiva sobre las decisiones - al estilo de la suma benthamiana de los placeres medibles o de la función bergsoniana de bienestar social-, al estudio de una racionalidad procedimental de las reglas de decisión. Más que la definición de unos criterios objetivos de eficiencia y de justicia distributiva, se busca el consenso en torno a los resultados alcanzados por los comportamientos racionales de los individuos, más que unas condiciones de orden, la regulación de la diversidad o el cambio inevitables. En esta búsqueda, los fines alcanzados no son un óptimo, sino la negociación, la transacción, el acuerdo y la tregua. Aunque estos fines - al menos frente a la hostilidad, el choque, la imposición y la dominación, que aparentemente serían sus alternativas - no dejan de implicar una cierta toma de partido en el terreno de los juicios de valor.

\section{Conclusión}

Por todo ello, puede parecer que el utilitarismo tiene hoy, al revés de lo que ocurría en los siglos xvin y xIx, mayor capacidad explicativa que normativa, o, al menos, que ésta se centra únicamente en las reglas de decisión $\mathrm{y}$ no en el contenido de las decisiones mismas.

Los cambios del enfoque pueden resumirse así: la definición de qué es la utilidad se ha ido trasladando desde el placer sensual al bienestar económico y a la más ecléctica y abierta de la satisfacción de los deseos humanos. La capacidad decisoria sobre la aplicación del principio de la utilidad se ha ido dejando de atribuir a un filósofo esclarecido, un gobernante ilustrado o un economista competente para ser reconocida como atributo de todos los individuos afectados, lo cual supone que el único legitimador de los fines de la sociedad es el consenso entre sus miembros. De este modo, la búsqueda de una racionalidad de los fines ha ido dejando paso a una racionalidad instrumental o deliberativa con la que los seres humanos puedan guiar sus conductas de un modo acorde con sus variados intereses y diversas opciones morales.

Es una panorámica de dos siglos; los supuestos y valores del utilitarismo han demostrado, pues, su fecundidad. En cuanto al desfase entre ciencia económica y ciencia política, la situación puede expresarse con palabras de Brian Barry: «No es difícil comprender la poderosa atracción que la economía ejerce en las otras ciencias sociales, puesto que durante largo tiempo poseyó una estructura teórica más llamativa que la de aquéllas. El problema quizá debería plantearse así: ¿por qué se pospuso durante tanto tiempo el intento de aplicar (al análisis de la política) la teoría económica? Los primeros utilitaristas —en especial, Bentham y James Mill- aplicaban sus métodos tan satisfactoria- 
mente a la política como a la economía. Los resultados pueden parecer algo toscos, pero a mi juicio lo importante es saber si la teoría política de James Mill representa una ampliación más exagerada que, por ejemplo, la teoría económica de Ricardo. La diferencia reside. por supuesto, en que las ideas de Ricardo fueron refinadas por teóricos subsiguientes, mientras que el Essay on Government de James Mill no tuvo prácticamente sucesores hasta la década de 1960" (Los sociólogos, los economistas y la democracia, 1970). Estas son, más o menos, las dimensiones del gap. 